\title{
Role of magnetic resonance imaging in ankle sprains
}

\begin{abstract}
Background and objective: Musculoskeletal injuries frequently occur in the ankle in both the athletic and general population. Ankle sprains are among the most frequent types of ankle injuries, which are conventionally diagnosed through clinical examinations. However, magnetic resonance imaging can provide a more precise diagnosis, leading to better injury management and prevention of consequent chronic complications. The present study aimed to examine the significance of magnetic resonance imaging in detecting and assessing changes that occur in ligaments and soft tissues in patients with ankle sprains.

Methods: In a prospective study, 50 patients with ankle sprain referred to Rizgary and Erbil Teaching hospitals in Erbil city, Iraqi Kurdistan Region, from March 2018 to April 2019, were included in the study. They underwent clinical evaluation and MRI (GE general electric 1.5 Tesla). Two expert radiologists analyzed the magnetic resonance imaging images, and the results were compared. The collected data were analyzed using SPSS version 23 through descriptive statistics.
\end{abstract}

Results: Most patients (64\%) belonged to the age groups of $30-49$ years old. Most of them $(64 \%)$ were males. Most events of ankle sprain $(66 \%)$ were because of sports and accidents. The clinical evaluation proved $82 \%$ of the ankle sprains. Regarding the laterality of the lesions, $60 \%$ were spotted in the right ankles and $40 \%$ in the left. According to magnetic resonance imaging results, both radiologists diagnosed that the ankle sprains included bone lesions, ligament injury, tendon injury, and effusion. There was an agreement of $\geq 96 \%$ between the two radiologists in this regard. The two radiologists were not significantly different in terms of diagnosing the ligament side. As reported by the radiologists based on the magnetic resonance imaging images, the anterior, lateral, and medial tendons were normal in most cases.

Conclusion: Magnetic resonance imaging is a vitally important tool that can be utilized reliably and accurately to diagnose and evaluate changes in ligaments and soft tissues in patients with ankle sprains.

Keywords: Magnetic resonance imaging (MRI); Ankle sprain; Ligaments; Injuries.

\section{Introduction}

The ankle joint has been referred to be as one of the most common parts of the body that encounters musculoskeletal injuries, such that ankle injuries occur in $12.2 \%$ of the athletic population, ${ }^{1}$ and $5.23 \%$ in the general population. ${ }^{2}$ Ankle sprains are among the most common types of ankle injuries, which can lead to chronic pain and instability. ${ }^{3-5}$ Most cases of ankle sprain injuries are associated with a lateral ligamentous complex which involves the posterior talofibular ligament (PTFL), the calcaneofibular ligament (CFL), and the anterior talofibular ligament (ATFL). ${ }^{6-8}$ Bony and cartilaginous structures guide the movement in the ankle joint. This movement is also controlled by tendons and ligaments, which prevent excessive valgus and varus of the ankle joint. ${ }^{9}$ Deltoid ligament and anterior talofibular ligament cause the capsule of the ankle joint to

${ }^{1}$ Koya General Directorate of Health, Ministry of Health, Erbil, Iraq

${ }^{2}$ Department of Surgery, College of Medicine, Hawler Medical University, Erbil, Iraq.

* Correspondence: nawrozdhahr@yahoo.com 
become medially and laterally thick, respectively. ${ }^{10}$ Regularity and harmony among the surfaces, ligaments, and tendons of the ankle provide $100 \%$ of its stability, which can be disturbed due to the ankle sprain. ${ }^{11}$ Accidental twisting, external forces, or trauma can lead to injury of one or more ligaments of the ankle joint, which is called ankle sprain. Ankle sprains can cause loss of normal biomechanics of the ankle and its functional instability. In acute and repeated cases, they lead to osteochondral changes and chronic instability and symptoms. ${ }^{5}$ History and physical examinations are the first lines of evaluation in case of ankle sprain, such that immediate swelling and restricted movement are associated with a complete ligament tear. Delayed initiation of swelling and partially limited movement are usually described in cases with partial ligamental injury. ${ }^{12}$ In addition to history and physical examination, conventional radiography has been introduced as the first imaging modality for diagnosis of ankle sprain; however, magnetic resonance imaging (MRI) is the best imaging method that provides both diagnosis and evaluation of ankle sprains, including both bony and soft tissue abnormalities. ${ }^{13}$ The superiority of MRI in diagnosing and assessing ankle injuries and sprains has been attributed to its capability to evaluate complex osseous, tendons, ligaments, and soft tissues of the ankle joints. It is also attributed to its ability to provide high-contrast quality images in multiple planes, which allow for dynamic study of the injured ankle joints. ${ }^{14}$ However, the accuracy of MRI and the reliability of its finding have been reported to be associated with great variability. 15 Its accuracy in detecting osteochondral lesions in the talus and peroneus brevis tendon tears was reported to be $80 \%$, ${ }^{16}$ while it was reported to be $19 \%$ in detecting cartilage lesions found at surgery. ${ }^{17}$ Therefore, it has been reported that accuracy, sensitivity, and specificity of MRI depend on the type of injuries in the ankle and the foot parts that are involved. ${ }^{18}$
Moreover, studies of lateral ankle ligamentous complex have reported different specificities and sensitivities for detecting CFL and ATFL tears. ${ }^{19,20}$ Given the high prevalence rate of ankle sprains in the general population and their negative effects on the patients' quality of life and probable chronic effects, the present study aimed to examine the value of MRI in diagnosing and evaluating changes in the ligaments and soft tissues in patients with ankle sprains.

\section{Methods}

\section{Study design and setting}

A prospective study was carried out at Rizgary and Erbil Teaching hospitals in Erbil, Iraqi Kurdistan region, from March 2018 to April 2019.

\section{Sample size and sampling method:}

Convenience sampling was used to select the study sample, which consisted of 50 patients. They were selected among patients referred to the Radiology Department to have an MRI scan during the period mentioned above. All of the patients referred to Rizgary and Erbil Teaching hospitals because of ankle sprain were considered the study sample. However, those with an open ankle injury and bone fracture were excluded from the study.

\section{Data collection}

In order to collect the required data, MRI was performed with GE general electric 1.5 Tesla. For this purpose, the patients were positioned in a powerful magnetic field in supine position with feet first, ankle angle of 90 degrees. A specialized surface coil (standard extremity coil) was used with a $12-16 \mathrm{~cm}$ field of view to take images of the foot and ankle with sufficient resolution and quality. Two radiologists analyzed the obtained images, and the results were compared. There were three standard planes for imaging of ankle joint, including sagittal, coronal, and axial planes, and each of them was used for a specific type of ankle injury. Tendons were evaluated with the coronal plane, ligaments with axial 
and coronal planes, bony lesions such as the lower tibia, fibula, and talus with both sagittal and coronal planes. Moreover, slice thickness of less than $3 \mathrm{~mm}$, and in some cases for larger lesions slice thickness of $5 \mathrm{~mm}$, was employed. The pulse sequences used for imaging of the ankle joints were T1 weighted image, T2 weighted image, gradient echo sequences, and fat suppressed.

\section{Statistical analysis}

Data had been entered and analyzed using the statistical package for the social sciences (SPSS, version 23). Numerical variables were presented as means and standard deviations. Categorical variables were summarized and presented as proportions. McNemar test was used to show whether there were significant differences between the two radiologists (examining the same sample of patients). Kappa statistics was calculated to assess the agreement between the two radiologists. A $P$ value of $\leq 0.05$ was considered statistically significant.

\section{Results}

Fifty patients with ankle sprain were included in the study. Their mean age was 38.24 years. The largest proportion of the sample $(38 \%)$ aged $30-39$ years. Two thirds $(64 \%)$ of the patients were males. The main cause of injury was accidents $(40 \%)$, followed by sport's injury $(26 \%)$, walking (18\%), and football (16\%). Clinical diagnosis detected 41 positive cases. Over half of the patients (54\%) had an MRI scan immediately after the injury. In most cases $(60 \%)$, the affected joint was the right one (Table 1).

Table 1: Baseline characteristics of patients.

\begin{tabular}{lcc}
\hline Variable & No. & (\%) \\
\hline Age (years) & 9 & $(18.0)$ \\
$<30$ & 19 & $(38.0)$ \\
$30-39$ & 13 & $(26.0)$ \\
$40-49$ & 9 & $(18.0)$ \\
$\geq 50$ & & \\
Gender & 32 & $(64.0)$ \\
Male & 18 & $(36.0)$ \\
Female & & \\
Injury & 13 & $(26.0)$ \\
Sporting & 20 & $(40.0)$ \\
Accident & 9 & $(18.0)$ \\
Walking & 8 & $(16.0)$ \\
Football & & \\
Clinical diagnosis & 41 & $(82.0)$ \\
Positive & 9 & $(18.0)$ \\
Negative & & \\
MRI timing after the injury & 27 & $(54.0)$ \\
Immediate & 10 & $(20.0)$ \\
After two weeks & 8 & $(16.0)$ \\
After four weeks & 3 & $(6.0)$ \\
After six weeks & 2 & $(4.0)$ \\
After eight weeks & & \\
Laterality & & $(40.0)$ \\
Left & 20 & $(60.0)$ \\
Right & 30 & $(100.0)$ \\
Total & 50 & \\
\hline & & \\
\end{tabular}


The MRI outputs were assessed by two radiologists. McNemar test was used to compare their opinions; however, no significant difference was found $(P>0.999)$. Kappa statistics was also used to evaluate the degree of agreement between the two radiologists, and the results indicated a high level of agreement (equal to or over $96 \%$ ) between them in all diagnosis cases (i.e., bone, ligament, tendon, and effusion) (Table 2). The two radiologists were compared in terms of their assessment of the lesions. The results of the McNemar test indicated that there was no significant difference between the radiologists in terms of ligament side, anterior tendon status, lateral tendon status, medial tendon status, lateral ligament status, and Achilles injury. Therefore, there was a high level of agreement between the radiologists in terms of their diagnosis of the lesions (Table 3).

Table 2: Main MRI findings as assessed by two radiologists.

\begin{tabular}{lcccccccc}
\hline & $\begin{array}{c}\text { Radiologist } \\
\mathbf{1} \\
(\mathbf{n}=\mathbf{5 0})\end{array}$ & $\begin{array}{c}\text { Radiologist } 2 \\
(\mathrm{n}=\mathbf{5 0})\end{array}$ & & & \\
$\begin{array}{l}\text { Lesions diag- } \\
\text { nosed }\end{array}$ & No. & $(\%)$ & No. & $(\%)$ & Agreement\% & Kappa† & $\boldsymbol{P}$ (McNemar) \\
\hline Bone & 18 & $(36.0)$ & 18 & $(36.0)$ & $96^{*}$ & 0.913 & $>0.999$ \\
Ligament & 28 & $(56.0)$ & 27 & $(54.0)$ & 98.0 & 0.960 & $>0.999$ \\
Tendon & 15 & $(30.0)$ & 15 & $(30.0)$ & $96^{*}$ & 0.905 & $>0.999$ \\
Effusion & 19 & $(38.0)$ & 19 & $(38.0)$ & 100.0 & 1.000 & $>0.999$ \\
\hline
\end{tabular}

tp values for all the Kappa statistics were $<0.001$

*One patient was diagnosed as positive by radiologist 1 and diagnosed as negative by radiologist 2 . Another patient was diagnosed as negative by radiologist 1 and positive by radiologist 2 . 
Table 3: Details of the lesions as assessed by two radiologists.

\begin{tabular}{|c|c|c|c|c|c|c|}
\hline & \multicolumn{2}{|c|}{ Radiologist 1} & \multicolumn{2}{|c|}{ Radiologist 2} & \multirow[b]{2}{*}{$P$ (McNemar) } & \multirow[b]{2}{*}{ Kappa } \\
\hline & No. & (\%) & No. & (\%) & & \\
\hline \multicolumn{7}{|c|}{ Ligament side } \\
\hline Lateral & 24 & $(85.7)$ & 23 & $(85.2)$ & & \\
\hline Medial & 4 & $(14.3)$ & 4 & $(14.8)$ & & \\
\hline Total & 28 & $(100.0)$ & 27 & $(100.0)$ & $>0.999$ & 1.000 \\
\hline \multicolumn{7}{|c|}{ Anterior tendon } \\
\hline Normal & 50 & $(100.0)$ & 50 & $(100.0)$ & NA & NA \\
\hline \multicolumn{7}{|c|}{ Lateral tendon } \\
\hline Normal & 46 & $(92.0)$ & 46 & $(92.0)$ & & \\
\hline PL & 1 & (2.0) & 0 & (0) & & \\
\hline PB & 2 & $(4.0)$ & 2 & $(4.0)$ & & \\
\hline $\mathrm{PL}+\mathrm{PB}$ & 1 & (2.0) & 2 & $(4.0)$ & & \\
\hline Total & 50 & $(100.0)$ & 50 & $(100.0)$ & NA & 0.868 \\
\hline \multicolumn{7}{|c|}{ Medial tendon } \\
\hline Normal & 40 & $(80.0)$ & 40 & $(80.0)$ & & \\
\hline TP & 7 & $(14.0)$ & 8 & $(16.0)$ & & \\
\hline FDL & 2 & $(4.0)$ & 0 & (0) & & \\
\hline $\mathrm{FHL}$ & 1 & (2.0) & 1 & (2.0) & & \\
\hline $\mathrm{FDL}+\mathrm{FHL}$ & 0 & $(0.0)$ & 1 & (2.0) & & \\
\hline Total & 50 & $(100.0)$ & 50 & $(100.0)$ & NA & 0.822 \\
\hline \multicolumn{7}{|c|}{ Lateral ligament } \\
\hline ATFL & 13 & $(54.2)$ & 14 & $(60.9)$ & & \\
\hline PTFL & 2 & (8.3) & 2 & (8.7) & & \\
\hline$A T F L+C F L$ & 3 & $(12.5)$ & 2 & (8.7) & & \\
\hline ATFL+PTFL & 6 & $(25.0)$ & 5 & $(21.7)$ & & \\
\hline Total & 24 & $(100.0)$ & 23 & $(100.0)$ & 0.368 & 0.857 \\
\hline \multicolumn{7}{|l|}{ Achilles } \\
\hline Yes & 6 & $(12.0)$ & 4 & (8.0) & & \\
\hline No & 44 & (88.0) & 46 & $(92.0)$ & 0.500 & 0.779 \\
\hline Total & 50 & $(100.0)$ & 50 & $(100.0)$ & & \\
\hline
\end{tabular}




\section{Discussion}

The present study was carried out to examine and evaluate the changes in the ligaments and soft tissues in patients with ankle sprains based on MRI images analyzed by two experienced radiologists. The analyzed data revealed that most of the patients belonged to the age groups 30 -39 and 40-49 years with 19 and 13 cases, respectively. Unlike the present study, which revealed that only $18 \%$ of the patients were under the age of 30 years, Martin et al. in 2013 reported that the incidence of ankle sprains is more frequent in individuals between 15 to 19 years of age. ${ }^{21}$ However, Tan et al. in 2016 reported that patients with ankle sprain aged 17-48 years with a mean age of 25.3 years, and this is in agreement with the findings of the current study. ${ }^{18}$ The results demonstrated that incidence of ankle sprains was more frequent among males than females, with respectively 32 and 18 cases. This finding is not in agreement with the results of the study carried out by Waterman et al. in 2010, who reported females over the age of 30 had a higher risk of experiencing ankle sprains than males in the same age group. ${ }^{22}$ Despite these findings, numerous studies have indicated that age and sex are not risk factors for ankle sprains. ${ }^{23-27}$ Regarding the causes of ankle sprain, the results showed that most cases $(40 \%)$ were due to accidents, followed by sports $(26 \%)$, walking $(18 \%)$, and football $(16 \%)$. This finding is in good agreement with the results of the studies carried out by Michaud et al. and Dekker et al., who reported similar causes for ankle sprains. ${ }^{28,29}$ It was also seen that clinical examination proved most of the ankle sprain events to be positive. This finding is in agreement with the reports of previous studies, which indicated that some clinical evaluations like crossed-leg test can be used to diagnose some types of ankle injury; ${ }^{30}$ however, its sensitivity and specificity are unknown. ${ }^{31}$ Based on the readings performed by the two experienced radiologists, it was concluded that they reported the same findings in most cases, which confirms the reliability of MRI in diagnosing ankle sprains. This finding is in line with the results of the study carried out by Digiovanni et al. in 2000, who reported that the diagnostic accuracy of MRI was $80 \%$ in the case of lateral ankle sprains. ${ }^{16}$ Howard et al. (2012) have also reported that MRI can be an effective tool to diagnose high ankle sprains and help with finding diagnostic alternatives. ${ }^{32}$ However, MRI has been reported to have an accuracy of about $19 \%$ in diagnosing cartilage lesions, which is not in line with the results of the present study. ${ }^{17}$ Moreover, it was seen that 18 patients $(36 \%)$ had bone lesions which have been reported to be frequent in ankle sprains. ${ }^{33}$ With regard to the type of bony lesions, the results showed that edema or bone bruise was the most frequent type. This finding is in line with the results of the study carried out by Ballester et al. in 2019, who reported that bone bruise is often observed in ankle sprains. ${ }^{34}$ It was also observed that the lateral ligament was more frequently involved in the injury than the medial ligament (24 vs. 4 cases). This finding is supported by the results of the studies carried out by Hootman et al. and Fernandez et al., who pointed out that lateral ankle sprains (LAS) are among the most common injuries of the ankle. ${ }^{35,36}$ The results also revealed that the anterior talofibular ligament (ATFL) was the most frequently involved ligament in ankle sprains. This finding is in good agreement with the reports by Melanson and Shuman, who stated that the anterior talofibular ligament (ATFL) is the most frequently injured ligament because it is the weakest ligament of the lateral ligament complex. ${ }^{37}$ Tendon was also found to be injured in 15 cases $(30 \%)$. This finding is in line with that of the study conducted by El-Liethy and Kamal. $^{38}$ Moreover, according to the results, lateral tendons, medial tendons, and Achilles were less involved in ankle sprains. This finding is supported by previously conducted studies. ${ }^{39,40}$ 
The results also showed that effusion was common among the patients who had an ankle sprain. This finding is in line with the results of the study carried out by Guillodo et al. ${ }^{41}$

\section{Conclusion}

MRI is vitally significant in diagnosing abnormalities of osseous and soft-tissue (including abnormalities of ligaments and tendons) in ankle trauma and plays a significant role in detecting lesions of tendons and ligaments. Therefore, MRI can help with the early diagnosis of bad consequences of ankle trauma and prevent the possible complications which may arise from delayed detection of ankle injury and abnormalities.

\section{Competing interests}

The authors declare no competing interests.

\section{References}

1. Doherty C, Delahunt E, Caulfield B, Hertel J, Ryan $\mathrm{J}$, Bleakley $\mathrm{C}$. The incidence and prevalence of ankle sprain injury: a systematic review and meta -analysis of prospective epidemiogical studies. Sports Med 2014; 44(1):123-40.

2. Nelson AJ, Collins CL, Yard EE, Fields SK, Comstock RD. Ankle injuries among United States high school sports athletes, 2005-2006. J Athl Train 2007; 42:381-7.

3. Fernandez WG, Yard EE, Comstock RD. Epidemiology of lower extremity injuries among US high school athletes. Acad Emerg Med 2007; 14(7):641-5.

4. McKay GD, Goldie PA, Payne WR, Oakes BW. Ankle injuries in basketball: injury rate and risk factors. Br J Sports Med 2001; 35(2):103 $-8$.

5. Anandacoomarasamy A, Barnsley L. Long term outcomes of inversion ankle injuries. $\mathrm{Br} \mathrm{J}$ Sports Med 2005; 39(3):e14.

6. Wang J, Hua Y, Chen S, Li H, Zhang J, Li Y. Arthroscopic repair of lateral ankle ligament complex by suture anchor. Arthroscopy 2014; 30(6):766-73.

7. Li HY, Hua YH, Wu ZY, Chen B, Chen SY. Strength of suture anchor versus trans-osseous tunnel in anatomic reconstruction of the ankle lateral ligaments: a biomechanical study. Arthroscopy 2013; 29(11):1817-25.

8. Fong DT, Hong Y, Chan LK, Yung PS, Chan KM. A systematic review on ankle injury and ankle sprain in sports. Sports Med 2007; 37(1):73-94.
9. Leardini A, O'Connor JJ, Giannini S. Biomechanics of the natural, arthritic, and replaced human ankle joint. J Foot Ankle Res 2014; 7(1):8.

10. Rayan S, Stephaine, McNicolas M, Eustace S. Anatomy for diagnostic imaging. $2^{\text {nd }}$ ed. Dublin, Ireland: Elsevier; 2004.

11. Espinosa N, Smerek J, Kadakia AR, Myerson MS. Operative management of ankle instability: Reconstruction with open and percutaneous methods. Foot Ankle Clin 2006; 11(3):547-65.

12. van den Bekerom MP, Kerkhoffs GM, McCollum GA, Calder JDF, van Dijk CN. Management of acute lateral ankle ligament injury in athletes. Knee Surg Sports Traumatol Arthrosc 2013; 21(6):1390-5.

13. Thomas H, Malone TR, Lynn N. Musculoskeletal imaging companion. $2^{\text {nd }}$ ed. USA: Book Holders; 2007.

14. Rosenberg ZS, Beltran J, Bencardino JT. MR imaging of the ankle and foot. Radiographics 2008; 20(1):153-79.

15. Watson AD. Ankle instability and impingement. Foot Ankle Clin 2007; 12(1):177e-95.

16. DIGiovanni BF, Fraga CJ, Cohen BE, Shereff MJ. Associated injuries found in chronic lateral ankle instability. Foot Ankle Int 2000; 21:809e15.

17. Rolf CG, Barclay C, Riyami M, George J. The importance of early arthroscopy in athletes with painful cartilage lesions of the ankle: a prospective study of 61 consecutive cases. J Orthop Surg Res 2006; 1(1):4.

18. Tan DW, Teh DJW, Chee YH. Accuracy of magnetic resonance imaging in diagnosing lateral ankle ligament injuries: A comparative study with surgical findings and timings of scans. Asia Pac J Sports Med Arthrosc Rehabil Technol 2016; 7:15-20.

19. Park HJ, Cha SD, Kim SS, Rho MH, Kwag HJ, Park $\mathrm{NH}$, et al. Accuracy of MRI findings in chronic lateral ankle ligament injury: comparison with surgical findings. Clin Radiol 2012; 67:3138.

20. Kumar V, Triantafyllopoulos I, Panagopoulos A, Fitzgerald S, van Niekerk L. Deficiencies of MRI in the diagnosis of chronic symptomatic lateral ankle ligament injuries. Foot Ankle Surg 2007; 13:171-6.

21. Martin R, Davenport T, Paulseth S, Wukich D, Godges J. Ankle instability and movement coordination impairments: ankle ligament strains-clinical practice guidelines linked to the International Classification of Functioning, Disability and Health for the Orthopaedic Section of the American Physical Therapy Association. J Orthop Sports Physical Therap 2013; 43(9): $1 \mathrm{~A}-40$.

22. Waterman BR, Owens BD, Davey S, Zacchilli MA, Belmont PJ Jr. The epidemiology of ankle sprains in the United States. J Bone Joint Surg 
Am 2010; 92(13):2279-84.

23. Arnason A, Sigurdsson SB, Gudmundsson A, Holme I, Engebretsen L, Bahr R. Risk factors for injuries in football. Am J Sports Med 2004; 32(1):5S-16.

24. Engebretsen AH, Myklebust G, Holme I, Engebretsen L, Bahr R. Intrinsic risk factors for acute ankle injuries among male soccer players: a prospective cohort study. Scand J Med Sci Sports 2010; 20(3):403-10.

25. Kofotolis $\mathrm{N}$, Kellis $\mathrm{E}$. Ankle sprain injuries: a 2-year prospective cohort study in female Greek professional basketball players. J Athl Train 2007; 42(3):388-94.

26. McHugh MP, Tyler TF, Tetro DT, Mullaney MJ, Nicholas SJ. Risk factors for noncontact ankle sprains in high school athletes: the role of hip strength and balance ability. Am J Sports Med 2006; 34:464-70.

27. Verhagen EA, Van der Beek AJ, Bouter LM, Bahr RM, Van Mechelen W. A one season prospective cohort study of volleyball injuries. Br J Sports Med 2004; 38(4):477-81.

28. Michaud PA, Renaud A, Narring F. Sports activities related to injuries? A survey among 9-19 year olds in Switzerland. Inj Prev 2001; $7(1): 41-5$.

29. Dekker R, Kingma J, Groothoff JW, Eisma WH, Ten Duis HJ. Measurement of severity of sports injuries: an epidemiological study. Clin Rehabil 2000; 14(6):651-6.

30. Kiter E, Bozkurt M. The crossed-leg test for examination of ankle syndesmosis injuries. Foot Ankle Int 2005; 26:187-8.

31. Lynch SA. Assessment of the Injured Ankle in the Athlete. J Athl Train 2002; 37(4):406-12.

32. Howard DR, Rubin DA, Hillen TJ, Nissman DB, Lomax J, Williams $\mathrm{T}$, et al. Magnetic resonance imaging as a predictor of return to play following syndesmosis (high) ankle sprains in professional football players. Sports Health 2012; 4(6):535-43.

33. Aurich M, Hofmann GO, Rolauffs B, Gras F. Differences in injury pattern and prevalence of cartilage lesions in knee and ankle joints: a retrospective cohort study. Orthop Rev (Pavia) 2014; 6(4):5611.

34. Ballester M, Lucar G, Saeedi S. Bone edema after ankle sprain and update. Biomed J Sci Tech Res 2019; 13(4):1028-9.

35. Hootman JM, Dick R, Agel J. Epidemiology of collegiate injuries for 15 sports: summary and recommendations for injury prevention initiatives. J Athl Train 2007; 42(2):311-9.

36. Fernandez WG, Yard EE, Comstock RD. Epidemiology of lower extremity injuries among US high school athletes. Acad Emerg Med 2007; 14(7):641-5.

37. Melanson SW, Shuman VL. Acute ankle sprain. Treasure Island (FL): Stat Pearls Publishing; 2019.
38. El-Liethy $\mathrm{N}$, Kamal $\mathrm{H}$. High resolution ultrasonography and magnetic resonance imaging in the evaluation of tendino-ligamentous injuries around ankle joint. The Egyptian Journal of Radiology and Nuclear Medicine 2016; 47(2):543-55.

39. Chinn L, Hertel J. Rehabilitation of ankle and foot injuries in athletes. Clin Sports Med 2010; 29(1):157-67.

40. Fong DT, Chan YY, Mok KM, Yung PS, Chan $\mathrm{KM}$. Understanding acute ankle ligamentous sprain injury in sports. Sports Med Arthrosc Rehabil Ther Technol 2009; 1(1):14.

41. Guillodo Y, Riban P, Guennoc X, Dubrana F, Saraux A. Usefulness of ultrasonographic detection of talocrural effusion in ankle sprains. J Ultrasound Med 2007; 26(6):831-6. 